\title{
Use of auctions to assess consumer value for milk from different packaging
}

\author{
Molly Paterson ${ }^{1}$ and Stephanie Clark ${ }^{2 *}$ (1) \\ ${ }^{1}$ Johnsonville LLC, PO Box 906, Sheboygan Falls, WI 53085 \\ ${ }^{2}$ Food Science and Human Nutrition Department, lowa State University, Ames 50011
}

\section{ABSTRACT}

The objective of this study was to evaluate the effect of a sensory experience and educational message on consumer value for fluid milk in different containers: translucent high-density polyethylene (HDPE), white-pigmented HDPE (light-block), and paperboard. We carried out 11 auction sessions $(\mathrm{n}=100)$. Sessions included an explanation of the experiment process; a survey about demographics and milk purchasing and consumption behaviors; a sensory evaluation; an educational message; and 3 rounds of $n$th price auctions. Consumers were blindly served 2 pairs of milk samples-2\% milk from paperboard and translucent HDPE, and skim milk from paperboard and translucent HDPE - and asked to indicate their preference and level of acceptability for each, using a 7-point hedonic scale. Consumers were asked to ascribe a monetary value to each sample. Consumers were also asked to taste and assess a value for $2 \%$ and skim milk from light-block HDPE. All milk samples were evaluated simultaneously by a panel of 9 judges who were trained to evaluate milk quality attributes on a $15 \mathrm{~cm}$ unstructured line scale. All milk was from the same industry source, processed and stored on the same timeline for each session. Results from the consumer panel on acceptability, trained panel descriptive analysis and consumer bids were analyzed using multi-factor ANOVA. Subjecting responses to pre- and post-surveys to $k$ means cluster analysis revealed 4 bidding populations in each round. Trained panelists detected higher levels of light-oxidized off-flavor in skim milk from translucent HDPE $(5.8 \mathrm{~cm})$ than from light-block HDPE $(2.42$ $\mathrm{cm})$ and in $2 \%$ milk from translucent $\operatorname{HDPE}(5.1 \mathrm{~cm})$ than from paperboard $(0.32 \mathrm{~cm})$. Although $84 \%$ of participants regularly purchased milk in plastic containers, consumers' acceptability scores for milk of the same fat content but from different packaging were not different. However, consumers gave higher acceptability scores

Received May 17, 2019.

Accepted October 28, 2019

*Corresponding author: milkmade@iastate.edu to $2 \%$ milk from paperboard $(5.2 / 7.0)$ than skim milk from paperboard $(4.7 / 7.0)$. We found no differences in consumer value (US\$) for $2 \%$ or skim milk in paperboard or translucent HDPE. However, after consumers received an educational message and tasted "Certified Fresh Taste" samples, they were willing to pay more for $2 \%$ milk in paperboard ( $\$ 0.31$ more) or HDPE ( $\$ 0.38$ more) packaging with a "Certified Fresh Taste" seal and for skim milk in paperboard ( $\$ 0.15$ more) or HDPE (\$0.21 more) packaging with a "Certified Fresh Taste" seal than for milk in packaging without such labeling. Although consumers could not detect a difference in the milk from different packages, they indicated that they would pay more for a "Certified Fresh Taste" seal after hearing about the effects of light on milk in different packaging, demonstrating the importance to consumers of external cues about freshness.

Key words: high-density polyethylene (HDPE), oxidation, sensory, shelf life

\section{INTRODUCTION}

Dairy products contain 9 essential nutrients important to the human body, including protein, calcium, potassium, phosphorus, vitamin $\mathrm{A}$, vitamin $\mathrm{D}$, vitamin $\mathrm{B}_{12}$, riboflavin, and magnesium (Heaney et al., 2011; Kliem and Givens, 2011). However, fluid milk consumption has been declining for decades. Annual per capita consumption in the United States was approximately $103 \mathrm{~L}$ in 1980, but fell to $65 \mathrm{~L}$ in 2017 (USDA-ERS 2019). According to Black et al. (2002), several factors may influence this national decline, including lactose intolerance $(40 \%)$, lifestyle choice $(18 \%)$, and bad taste $(42 \%)$.

Perceived or diagnosed cow's milk allergy and lactose intolerance play a role in driving consumers away from dairy milk (Donkor et al., 2007). Cow's milk allergy is prevalent in children, and often consumers choose total dairy avoidance as a result (Scurlock et al., 2005; Katz et al., 2013). Lactose maldigestion is more common in older adults and in certain ethnic populations (Jackson and Savaiano, 2013). Cow's milk allergy and lactose maldigestion and are 2 very different reactions to dairy, 
but consumers often confuse them, and sometimes the conditions overlap (Szilagyi and Ishayek, 2018).

Because of these types of issues, the desire for plantbased alternatives has increased (Sethi et al., 2016). The most recognizable alternatives include soy, almond, and coconut beverage, but many others are available, including oat, sunflower, hemp, and quinoa milk. In addition to the challenges of allergy or intolerance, some consumers see whole-fat dairy milk as being inferior to soy milk and reduced-fat milk in terms of nutrition (Bus and Worsley, 2003). Not only are consumers drinking more milk alternatives, but they are also consuming more of other beverages. Popkin (2010) reported that one of the biggest consumption shifts from the 1970s to 2007 was a doubled increase in sugar-sweetened beverages, and a small increase in juice consumption.

One factor limiting fluid milk consumption is its tendency to develop off-flavors. Milk should have a clean, delicate flavor that is slightly sweet because of the lactose, and it should have no unpleasant aftertaste (O'Connor and O'Brien, 2006; Alvarez, 2009). The combination of riboflavin in milk and exposure to light from a retail dairy case can induce light oxidation. Light-induced oxidation imparts an off-flavor that has been described as burnt, burnt feathers, wet cardboard, or brown paper towel, commonly coupled with a mouth-drying effect (Alvarez, 2009). This off-flavor is easily detected by trained and untrained panelists (Chapman et al., 2002; Webster et al., 2009; Walsh et al., 2015; Potts et al., 2017). Light-induced oxidation has been detected by untrained consumers in as little as 54 to $120 \mathrm{~min}$, well within the $8 \mathrm{~h}$ or longer that milk typically sits in retail dairy cases under lighting (Chapman et al., 2002).

In the United States, milk is available in a few different packaging materials, but translucent high-density polyethylene (HDPE) is the most common type. Translucent HDPE allows light from the store and retail case to pass through the packaging to the milk, and this enables light-induced oxidation. Milk packaging with pigmentation provides additional protection by blocking wavelengths that are detrimental to milk flavor quality. Webster et al. (2009) demonstrated that blocking wavelengths in the $400-600 \mathrm{~nm}$ range with over-wrapped iridescent films reduced (but did not completely eliminate) light-induced off-flavors. More recently, Potts et al. (2017) confirmed the effectiveness of pigmentation in extending milk quality under fluorescent and light-emitting diode (LED) lighting, conducted under 2 levels of exposure (960 and 1,460 lx).

To better meet consumer desires, an improved understanding is needed of consumer behaviors and value for milk. Every time a consumer makes a choice, their value for a product or its attributes is discovered. Tapping into revealed or stated preferences are some traditional approaches to elicit value (Hanley et al., 2006). Experimental auctions introduce a method that is non-hypothetical, wherein money is exchanged (Napolitano et al., 2008; Lusk and Shogren, 2009). Several different styles of auctions are used by economists to understand consumer value or willingness to pay for a good or service (Akaichi et al., 2012; Elbakidze et al., 2013). Typically, consumers are given several product options and in private, they submit their value for each. Depending on group size, several participants who bid higher than the "market value" (the $n$th price) purchase one of the product options (randomly selected), and money is exchanged. Auctions have been used to determine willingness to pay for goods such as beef steaks, organic milk, yogurt, kiwi, fish, cigarettes, cars, and coffee mugs (Hoffman et al., 1993; Bohm, 1994; Jaeger and Harker, 2005; Rousu et al., 2005; Napolitano et al., 2008; Akaichi et al., 2012; Alfnes et al., 2018).

The auction technique has not yet been used to investigate consumer value for milk. The objectives of this study were to determine consumer preferences and acceptability for $2 \%$ and skim milk from translucent HDPE, pigmented (light-block) HDPE, and paperboard packaging, as well as to understand consumer value for the same milk samples based on visual cues, taste, and an educational message using $n$th price auctions. We hypothesized that milk samples exposed to light and in translucent HDPE would have light-oxidized off-flavors that would warrant lower acceptability scores and lower stated values compared to milk from alternative packaging that blocked light or contained a "Certified Fresh Taste" seal (Figure 1).

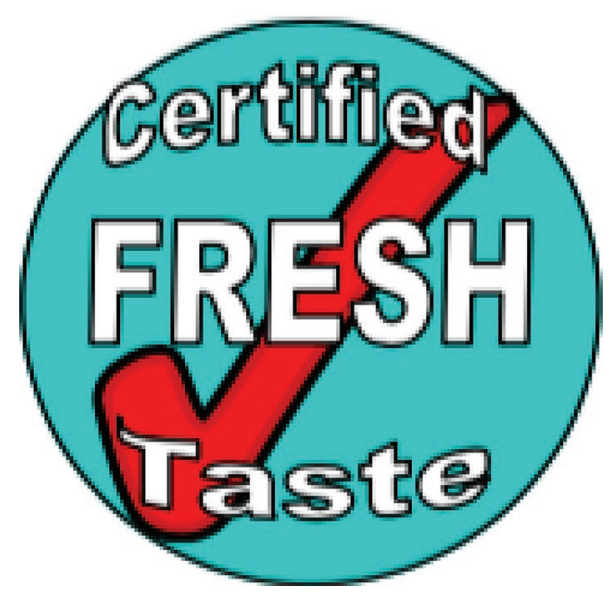

Figure 1. "Certified Fresh Taste" seal placed on packages of paperboard and light-block packaged milk. 


\section{MATERIALS AND METHODS}

\section{Timeline and Milk Production}

Milk samples were produced at Agropur Inc. Division Natrel USA (St. Paul, MN) under the Schroeder brand. Both $2 \%$ and skim milk products were produced in the same facility and followed the same timeline for each consumer panel. Samples were packaged by Agropur Inc. in half-gallon, light-block HDPE containers, halfgallon HDPE nonpigmented containers (translucent HDPE), and half-gallon paperboard cartons. Samples were produced on normal production days at the facility and were held on-site for our use. All samples were stored in Schroeder's warehouse under black plastic bags to eliminate light exposure and were transported in closed coolers and held at $4^{\circ} \mathrm{C}$ in a commercial refrigerator until use.

\section{Sample Preparation}

Samples in all 3 types of packaging were exposed to sensory kitchen lighting at the Research Center of the Center for Crops Utilization, Iowa State University (Ames, IA), at $1,300 \mathrm{~lx}$ for $1 \mathrm{~h}$ on the same day as the consumer and trained panel tasting sessions. Light intensity was measured with a light meter (General Electric, Cleveland, $\mathrm{OH}$ ). We selected 1,300 lx based on previous research and on the average lux of local refrigerated lighted dairy cases (Chapman et al., 2001). After light exposure, samples were stored at $4^{\circ} \mathrm{C}$ in a commercial refrigerator. Within $2 \mathrm{~h}$ of tasting for both trained and consumer panels, samples were poured into translucent polystyrene tasting cups (59 mL Dart Solo), lidded, and stored in the refrigerator on trays until tasting.

\section{Descriptive Analysis}

Nine people ( 3 men and 6 women) over the age of 18 yr were recruited from the university to participate in the sensory evaluation for this study. Seven panelists completed the training and evaluations (3 male and 4 female). Panelist requirements were to have no aversion to milk, to consume milk regularly, and to have interest in sensory evaluation. Panelists were recruited from the department or dairy products evaluation team, so that most had some understanding of evaluating dairy products before the study. Panelists were trained using quantitative descriptive analysis over 8 sessions of $1 \mathrm{~h}$. Six milk attributes (cooked, feed, flat, foreign, lacks freshness, and oxidized) were chosen for evaluation. These attributes were chosen from the milk- scoring guide for the National Collegiate Dairy Product Evaluation Contest (Alvarez, 2009) because they are common attributes that could change in milk based on processing or packaging and were expected to either develop or dissipate over time as milk was stored. For this study, panelists were instructed to recognize the descriptors based on the terms included in Table 1. Panelists received each milk sample in a lidded, disposable translucent polystyrene cup (59 mL Solo; Dart, Mason, MI) with a 3-digit label and were taught to put one hand on the bottom of the cup and swirl gently to release volatile compounds before tasting. Panelists were asked to sniff the headspace, note the aroma, and then take a mouthful of the sample while breathing in through the nose to observe volatiles. Panelists were introduced to varying degrees of defects on a $15-\mathrm{cm}$ unstructured line scale, ranging from slight $(3 \mathrm{~cm})$ to definite $(7.5 \mathrm{~cm})$ or pronounced $(13 \mathrm{~cm})$ levels. Research investigators prepared reference samples by purchasing or adulterating milk with safe compounds that reflected the off-flavors (Table 1). Scoring of the 6 attributes was agreed upon through discussion by the group and the research facilitator in the group sessions. Panelists were trained to taste milk in the same way throughout the training and the subsequent tastings.

For private testing sessions, each panelist was given a private booth and a unique 3 -digit panelist code. In the booth, panelists had a cup of tap water to cleanse their palate between samples, as well as a pencil and a blank paper ballot for each sample. Samples were randomly distributed, ballots were collected after each sample, and ratings were measured with a ruler by investigators and compiled in Excel (Microsoft, Redmond, WA). Trained panelists tasted samples at the same time as consumers, on 3 occasions, but at a different location.

\section{Consumer Session Organization}

Milk consumers $(\mathrm{n}=100)$ were recruited to participate in auction sessions using online postings, emails, flyers, and word of mouth. Inclusion criteria were as follows: over the age of $18 \mathrm{yr}$, purchasing milk at least once per month, and consuming milk at least twice per week. Volunteers were scheduled into 11 different auction sessions, each designed to accommodate up to 15 participants. Sessions were held at the Iowa State University Nutrition Wellness Research Center, in the Iowa State University Research Park, about 2 miles from the Iowa State University campus. A benefit of an off-campus location was improved potential to attract a wide range of milk consumers - not primarily college students. An additional benefit was free parking. A $\$ 30$ incentive was announced in the recruitment materials. 
Table 1. Selected terms, descriptors, and preparation method for descriptive analysis of milk

\begin{tabular}{|c|c|c|}
\hline Off-flavor & Descriptor & Preparation $^{1}$ \\
\hline Cooked & Custard, eggy, sulfur aroma & $\begin{array}{l}\text { Definite: Organic, ultra-pasteurized milk from paperboard } \\
\text { container }\end{array}$ \\
\hline Feed & Grassy, hay, stalky aroma & $\begin{array}{l}\text { Pronounced: Steep alfalfa hay in boiling water for } 2 \mathrm{~min} \text {; filter } \\
\text { tea through coffee filter; add } 15 \mathrm{~mL}\end{array}$ \\
\hline Flat & $\begin{array}{l}\text { Watered down, thinner mouth feel, and less dairy } \\
\text { fat/cream flavor than } 2 \%\end{array}$ & $\begin{array}{l}\text { Definite: } 1 \% \text { milk } \\
\text { Pronounced: skim milk }\end{array}$ \\
\hline Lacks freshness & $\begin{array}{l}\text { Flavors that would indicate storage or bacterial } \\
\text { growth in milk (e.g., acid/sour, barny, bitter, fecal, } \\
\text { fermented, fruity) }\end{array}$ & $\begin{array}{l}\text { Slight: Open milk and leave in refrigerator for } 3 \mathrm{~d} \text { before tasting } \\
\text { Definite: Open milk and leave in refrigerator until expiration } \\
\text { date }\end{array}$ \\
\hline Oxidized light $^{2}$ & $\begin{array}{l}\text { Smells like wet brown paper towel, cardboard, } \\
\text { mouth-drying }\end{array}$ & $\begin{array}{l}\text { Slight: Milk in translucent high-density polyethylene purchased } \\
\text { directly from lighted store case }\end{array}$ \\
\hline Oxidized metal ${ }^{2}$ & $\begin{array}{l}\text { Copper penny or metallic aroma/taste, tingling } \\
\text { sensation, puckering }\end{array}$ & $\begin{array}{l}\text { Definite: Milk in translucent high-density polyethylene exposed } \\
\text { to direct sunlight exposure for } 10 \mathrm{~min} \\
\text { Pronounced: Extend exposure to } 20 \mathrm{~min} \\
\text { Slight: } 1: 4 \text { dilution of pronounced defect } \\
\text { Definite: } 1: 2 \text { dilution of pronounced defect } \\
\text { Pronounced: Prepare } 0.25 \% \text { copper sulfate solution; add } 2 \mathrm{~mL} \\
1-2 \text { h before training }\end{array}$ \\
\hline
\end{tabular}

\footnotetext{
${ }^{1}$ All adulterants were added to $590 \mathrm{~mL}$ of $2 \%$ milk packaged in paperboard.

${ }^{2}$ Panelists were to indicate the type of oxidation, followed by rating intensity.
}

Volunteers were not told in advance that auctions were to be conducted, or that milk would be available for sale.

Panelists were handed a 3-digit-coded folder upon arrival, which contained all of the paperwork related to the day, organized in a specific order, with a printed stop sign between sections to prevent participants from moving ahead before instructed to do so. Panelists were seated at round tables with trifold cardboard barriers (0.75 $\mathrm{m}$ high) that enabled privacy for writing on paper surveys and ballots during sessions.

Every session was conducted in the same fashion using a "script" read by one facilitator, so that all auction participants experienced a very similar event. Every session consisted of an explanation of the consent form and experiment process, a pre-survey, a sensory evaluation, an educational message, auctions, and a postsurvey.

Panelists first signed consent forms and filled out the pre-survey, which contained with 32 questions about demographics (6), knowledge (5), purchasing practices (18), and consumption behavior (3). Panelists were given time to answer all questions unless one panelist was holding up the group, in which case that panelist was allowed to return to the survey at the end of the session to complete it. Questions directly related to the study that could "prime" panelists to the intent of the study, were not asked; those questions were included in a post-survey (11 questions). For instance, no question asked about participants' knowledge of the effects of light exposure on milk.
Consumers were served 4 milk samples in 2 sets. All panelists received the same paired samples (2 samples of $2 \%$ milk, 1 from paperboard and 1 from translucent HDPE) and 2 samples of skim milk (1 from paperboard and 1 from translucent HDPE), but the sample order was randomized. First, panelists were instructed to indicate a preference in each pair. Then, they were instructed to rate the acceptability of each sample on a 7-point hedonic scale. Consumers were strongly encouraged to take notes on paper to help them remember what they liked or disliked about samples, because the information would be used later. Because preference does not quantify level of liking and acceptability alone does not always indicate preference (in cases of central tendencies or high variability), we conducted both preference and acceptability tests. Tests were conducted in sequence to minimize fatigue.

We conducted 3 rounds of $n$th price auctions based on the description in the next section. Finally, consumers filled out a post-survey with additional questions about purchasing and information gained from the session. Although we allotted $90 \mathrm{~min}$ for each session, no session exceeded 80 min.

\section{Auctions}

To determine consumers' willingness to pay for and true value for certain attributes of fluid milk, we used $n$th price auctions (Lusk and Shogren, 2009).

Consumers in all sessions were treated in the same fashion, but we found 4 balanced variations related 
to disbursement of the $\$ 30$ incentive. For half of the sessions, panelists underwent asset integration at the beginning; asset integration involved asking panelists to think about and write down up to 4 ways they might spend the $\$ 30$. Then, panelists received the $\$ 30$ at the beginning of the session for half of the sessions, and at the end for the other half. In summary, one-fourth of the panelists underwent asset integration and were given $\$ 30$ at the beginning; one-fourth of the panelists underwent asset integration and were given $\$ 30$ at the end; one-fourth of the panelists did not undergo asset integration and were given $\$ 30$ at the beginning; and one-fourth of the panelists did not undergo asset integration and were given $\$ 30$ at the end.

Consumers in all sessions were introduced to the concept of auctions and practiced 3 rounds of auctions using an unrelated set of items - in this case, candy bars. For the first practice round with candy bars, the process involved 5 steps: (1) Facilitators carried in trays containing the 4 candy bars that were up for auction and allowed panelists to look at them and touch them. (2) Panelists were instructed to write a bid (the most they were willing to pay) for every candy bar on a bidding sheet. (3) Facilitators revealed the winning product (previously selected at random, written down, and sealed in an envelope). (4) Facilitators wrote the highest bids (up to the $n$th price) for the winning product on a flip chart, in order. The number of consumers in each session was divided in half to determine $n$. When an odd number of people were present, the number was rounded up (e.g., 6 for 11 people). (5) Facilitators circled the winning bid - the $n$th bid - the price to be paid for the winning product.

In the second practice round, all of the steps were the same, except step 4 was skipped (this step was also skipped in all milk auctions). Facilitators privately wrote down the top bids and did not publicly reveal them. They revealed only the single winning bid (the price to be paid for the winning product).

The third practice round was the same as the second practice round, except that an additional step was added: real money was exchanged for the winning product. All participants who submitted bids higher than the winning ( $n$ th) bid paid that amount of money for the candy bars. Candy bars were distributed to the winners, and the winners paid for them. Any remaining questions were answered before proceeding to the real auctions of interest, with milk.

For the milk auctions, the steps were similar, with slight modifications. Consumers were asked to submit a value for milk in a total of 3 rounds: in round 1, they bid on products shown to them in actual packaging; in round 2, they bid on the 3-digit-coded samples associated with those they tasted during the blind tasting earlier in the session; and in round 3, they listened to an educational message and then bid on a set of products described on a bidding sheet. No panelists' bids were publicly revealed. After round 3 was completed, a single winning product was revealed, the $n$th price was revealed, and those who bid higher than the $n$th price exchanged money for the milk. The process is described in more detail below.

At the beginning of the first round, panelists were shown 4 milk products that were available in local stores (HyVee, Ames, IA), along with the actual local market prices for each. Products included 1 gallon of HyVee brand $2 \%$ milk in translucent HDPE (\$3.29), a half-gallon of Horizon Organic 2\% milk in paperboard (\$3.99), a half-gallon of Anderson Erickson skim milk in translucent HDPE (\$2.19), and a quart of Anderson Erickson 1\% milk in paperboard (\$1.49). These products were not available for sale, but were shown to assist consumers in remembering the typical market price for milk.

Next, consumers were shown the 4 experimental auction milk samples $(2 \%$ and skim milk in paperboard and translucent HDPE) in their original containers and told that those 4 options were part of the auction. Schroeder products were not available in the local markets, so the products should have been completely new to all participants. Panelists were allowed to take the milk containers out of the ice basins, look at them more closely, and ask questions. Consumers were then instructed to write down a monetary value for each container of milk using the bidding sheet provided (Figure 2). All were given enough time to think and write before proceeding (approximately $3 \mathrm{~min}$ ).

In the second round, consumers were instructed to consider what they had tasted earlier in the session, along with the appearance of the packages just observed, and then assign monetary values to each of 8 samples listed on their bidding sheet (Figure 3). Eight options were available because both light-block and translucent

Panelist \#

Product My Bid

Reduced Fat Milk (2\%), Plastic

Skim Milk, Plastic

Reduced Fat Milk (2\%), Paperboard

Skim Milk, Paperboard

Figure 2. Bidding sheet provided to panelists in auction round 1 , where panelists were asked to assess a value for each milk shown to them, considering fat level (skim or $2 \%$ ) and container style [paperboard or high-density polyethylene ("plastic")]. 
HDPE packaging, as well as paperboard, were available for skim and $2 \%$ milk. Panelists were instructed to refer back to their written comments about the 4 samples in the blind tasting while indicating preference and level of acceptability. The 3-digit codes of the samples they had tasted earlier were listed twice; once paired with paperboard, and once paired with HDPE. This step was important for eliciting the value consumers placed on the products when packaging was coupled with a sensory experience (without adding to fatigue by having them taste 4 samples a second time).

In round 3, consumers were read the following educational message:

As you probably have noticed, milk is packaged in several kinds of containers. Have you ever wondered if package style can influence the milk inside? When milk sits in the lighted refrigerated dairy case, if the milk is not protected from the light, the light can initiate chemical reactions. A study at Cornell University showed that consumers noticed a flavor defect after milk had been exposed to light for as little as 54 minutes. Not only is flavor affected, but vitamin $\mathrm{A}$ and the $\mathrm{B}$ vitamin riboflavin are reduced. The scientific term for that milk is "oxidized." When milk is packaged in paperboard, the packaging does not allow this process to occur. Technology has also been developed to inhibit this process from happening in plastic jugs. To help consumers make better choices, a new label "Certified Fresh Taste" is being considered. For milk to earn the right to carry this label, both chemical analysis and a trained panel of experts must affirm that milk in such packaging has no detectable oxidized flavor defects. We will now provide you with skim milk that has earned "Certified Fresh Taste" and 2\% milk that has earned "Certified Fresh Taste."

While they listened to the message, consumers were shown the same packages as in round 1 (in ice basins), but 2 additional milk samples were shown: skim and $2 \%$ milk in light-block HDPE, both with a "Certified Fresh Taste" seal affixed. Consumers were then served each of the new samples (in lidded cups with 3-digit codes) and told that they had "earned" the "Certified Fresh Taste" seal. They were asked to taste the samples and write down any comments they had about them before bidding.

For the final bidding session (still round 3), consumers were asked to assign values to milks using of all the information they had gained during the session: a visual of packaging types, blind tasting, an educational message about the effect of light on milks in different
Paneilist

Product My Bid

Reduced Fat MIIk (2\%), Plastic,

Tastes Llke Sample 532

$5 \mathrm{kim}$ MIIk, Plastic,

Tastes Like Sample 853

Reduced Fat MIIk ( $2 \%$ ), Paperboard

Skim Mllk, Paperboard

Tastes Like Sample 566

Reduced Fat Milk ( $2 \%$ ), Plastic

Tastes Llke Sample 751

Skim Milk, Plastic

Tastes Llke Sample 566

Reduced Fat Mllk (2\%), Paperboard

Tastes Like Sample 532

5 kim Milk, Paperboard

Tastes Llke Sample 853

Figure 3. Bidding sheet provided to panelists in auction round 2 , where panelists were asked to assess a value for 8 possible milk options, considering fat level (skim or 2\%), container style [paperboard or high-density polyethylene ("plastic")], and sensory experience (what they wrote about samples they had tasted earlier in the session; 3-digit numbers corresponded to those tasted by participants in respective sessions).

packaging, the absence or presence of a "Certified Fresh Taste" seal on the package, and tasting of milk from light-block HDPE packaging. Samples and their packaging types were provided on bidding sheets (Figure 4). Consumers were asked to assess a value for each of the following 8 options: skim or $2 \%$ milk from light-block HDPE with the "Certified Fresh Taste" seal; skim or $2 \%$ milk from translucent HDPE; skim or $2 \%$ milk from paperboard with a "Certified Fresh Taste" seal; and skim or $2 \%$ milk from paperboard without the seal.

Finally, as in the candy practice session, at the end of round 3 , the randomly selected milk was revealed. The $n$th price (or market price) was paid by all consumers who bid higher than that price. Consumers completed the session by filling out an 11-question post-survey. The session was concluded by handing all consumers a lined grocery bag provided by the Midwest Dairy Association, and $\$ 30$ in cash (for those who received cash at the end).

\section{Statistical Analysis}

We performed statistical analyses of trained panel data, consumer survey and sensory data, and consumer 
$n$th price auction data using JMP Pro 14.0 (SAS Institute Inc., Cary, NC). We conducted predictor screening to narrow down the demographic, knowledge, purchasing, and consumption factors (43 pre-survey and postsurvey responses) and hedonic responses that were the most viable predictors of variability in the auction bids. We conducted multi-factor ANOVA (3-way) using the greatest predictors ("fat content typically purchased," "package typically purchased," and "frequency of consumption"), with Tukey-Kramer multiple pairwise comparison adjustment, considering a significance level of $P<0.05$. The demographic, knowledge, purchasing and consumption variables best at explaining variability in bids were subjected to $k$ means cluster analysis, which was appropriate for grouping people based on their bidding behavior for multiple goods (Lusk and Shogren, 2009). Differences in cluster means were considered significant when 1-way ANOVA with the Tukey-Kramer test resulted in $P<0.05$.

\section{RESULTS AND DISCUSSION}

\section{Descriptive Analysis}

The trained panelists evaluated 6 attributes related to the 6 milk products the consumer panelists tasted (skim and $2 \%$ milk from paperboard, translucent HDPE, and light-block HDPE) on 3 occasions (Table 2). Three-way ANOVA confirmed that there was no panelist effect $(P>0.05)$, that the "flat" attribute was driven by fat content $(P<0.0001)$, and that the oxidized off-flavor was driven by packaging $(P<0.0001)$. We found fat $\times$ panelist and fat $\times$ panelist $\times$ date interactions for the "flat" attribute $(P<0.05)$, but because "flat" was not the key descriptor of interest for the study, these interactions were not considered problematic.

Light-oxidized was the descriptor of interest, and was used to monitor the effect of light exposure on milk acceptability and auction bidding by consumers. For skim milk, mean scores for light-oxidized flavor were

\begin{tabular}{|c|c|}
\hline Product & My Bid \\
\hline \multicolumn{2}{|l|}{$\begin{array}{l}\text { Reduced Fat Mllk (2\%), Plastic; } \\
\text { Regular }\end{array}$} \\
\hline $\begin{array}{l}\text { Skim Milk, Plastic, } \\
\text { Regular }\end{array}$ & \\
\hline \multicolumn{2}{|l|}{$\begin{array}{l}\text { Reduced Fat MIlk (2\%), Paperboard } \\
\text { Regular }\end{array}$} \\
\hline \multicolumn{2}{|l|}{$\begin{array}{c}\text { Skim Milk, Paperboard } \\
\text { Regular }\end{array}$} \\
\hline \multicolumn{2}{|l|}{$\begin{array}{c}\text { Reduced Fat Mllk }(2 \%) \text {, Plastic } \\
\text { Certifled Fresh Taste }\end{array}$} \\
\hline \multicolumn{2}{|l|}{$\begin{array}{l}\text { Skim Milk, Plastic } \\
\text { Certified Fresh Taste }\end{array}$} \\
\hline \multicolumn{2}{|l|}{$\begin{array}{c}\text { Reduced Fat Mllk ( } 2 \%) \text {, Paperboard } \\
\text { Certifled Fresh Taste }\end{array}$} \\
\hline $\begin{array}{l}\text { Skim Milk, Paperboard } \\
\text { Certifled Fresh Taste }\end{array}$ & \\
\hline
\end{tabular}

Figure 4. Bidding sheet provided to panelists in auction round 3, where panelists were asked to assess a value for each milk, considering fat level (skim or $2 \%$ ), container style [paperboard with or without "Certified Fresh Taste" seal; translucent high-density polyethylene ("plastic"); light-block high-density polyethylene with "Certified Fresh Taste" seal], and sensory experience.

higher for milk from translucent HDPE than for milk from light-block packaging $(P<0.05$; Table 2$)$; mean scores for skim milk from paperboard did not differ from either of the other products. For $2 \%$ milk, mean scores for light-oxidized flavor were higher for milk from translucent HDPE than for milk from paperboard $(P<0.05$; Table 2$)$; mean scores for $2 \%$ milk from light-block HDPE did not differ from either of the other products. Light-block packaging does not block $100 \%$ of the light, but has been reported to be more effective than nonpigmented packaging in decreasing

Table 2. Mean scores of 7 trained panelists for skim milk and $2 \%$ milk exposed to light

\begin{tabular}{lcccccc}
\hline Treatment $^{1}$ & Cooked & Feed & Flat & Foreign & $\begin{array}{c}\text { Lacks } \\
\text { freshness }\end{array}$ & Oxidized \\
\hline Skim HDPE & $0.39^{\mathrm{a}}$ & $0.17^{\mathrm{a}}$ & $13.53^{\mathrm{a}}$ & $0.00^{\mathrm{a}}$ & $0.79^{\mathrm{a}}$ & $5.78^{\mathrm{a}}$ \\
Skim paperboard & $0.06^{\mathrm{a}}$ & $0.00^{\mathrm{a}}$ & $12.84^{\mathrm{a}}$ & $0.51^{\mathrm{a}}$ & $0.54^{\mathrm{a}}$ & $3.01^{\mathrm{abc}}$ \\
Skim light-block HDPE & $0.94^{\mathrm{a}}$ & $0.08^{\mathrm{a}}$ & $13.53^{\mathrm{a}}$ & $0.49^{\mathrm{a}}$ & $1.09^{\mathrm{a}}$ & $2.42^{\mathrm{bc}}$ \\
$2 \%$ HDPE & $1.26^{\mathrm{a}}$ & $0.00^{\mathrm{a}}$ & $0.00^{\mathrm{b}}$ & $0.93^{\mathrm{a}}$ & $0.52^{\mathrm{a}}$ & $5.05^{\mathrm{ab}}$ \\
$2 \%$ paperboard & $1.05^{\mathrm{a}}$ & $0.00^{\mathrm{a}}$ & $0.06^{\mathrm{b}}$ & $0.00^{\mathrm{a}}$ & $0.74^{\mathrm{a}}$ & $0.32^{\mathrm{c}}$ \\
$2 \%$ light-block HDPE & $1.51^{\mathrm{a}}$ & $0.00^{\mathrm{a}}$ & $0.00^{\mathrm{b}}$ & $0.00^{\mathrm{a}}$ & $0.54^{\mathrm{a}}$ & $2.08^{\mathrm{bc}}$ \\
\hline
\end{tabular}

${ }^{a-c}$ Means in the same column with different superscripts were significantly different $(P<0.01)$; scores based on a 15 -cm line scale.

${ }^{1} \mathrm{HDPE}=$ high-density polyethylene. 
the degradation of vitamins because of light, as well as preventing oxidized off-flavors (van Aardt et al., 2001; Webster et al., 2009). Based on the intensity of light exposure and duration of exposure, these results were in line with those of other studies (Chapman et al., 2002; Potts et al., 2017).

\section{Consumer Demographics, Pre-Survey, Preference, and Acceptability}

Consumers $(\mathrm{n}=100)$ recruited for the in-person sessions were $57 \%$ women and $43 \%$ men and ranged in age from 18 to $>55 \mathrm{yr} ; 50 \%$ of participants were above a range from 35 to $44 \mathrm{yr}$, and $50 \%$ were below that range. Although we initially planned for sessions of 10 to 12 participants, because of varying attendance participation ranged from 5 to 15 in each session. Of all participants, $40 \%$ lived in 2-person households, $23 \%$ lived in households or 4 or more, $20 \%$ lived alone, and $17 \%$ lived with 2 others. Thirty-four percent had 4-year college degrees, $23 \%$ had some college, $20 \%$ had a master's degree, $15 \%$ had a doctoral degree, and the remainder had other levels of education. The majority of participants $(77 \%)$ indicated that they were the primary milk purchaser in their household; $90 \%$ of those indicated that they drink milk as a beverage (not simply in recipes or in cereal) at least once a week. Of all respondents, $90 \%$ indicated that they drank milk once a week or more frequently ( $36 \%$ multiple times a week, $28 \%$ at least once a day, and $19 \%$ multiple times a day). An even higher number $(97 \%)$ indicated that they consumed milk (e.g., as a beverage, on cereal, in coffee, in recipes) once a week or more frequently ( $34 \%$ multiple times a week, $26 \%$ once a day, and $34 \%$ multiple times a day). Of all respondents, $47 \%$ purchased skim milk, $18 \%$ purchased low-fat (1\%) milk, $15 \%$ purchased reduced-fat $(2 \%)$ milk, $12 \%$ purchased whole milk, and $8 \%$ purchased something else, such as chocolate milk. Of those who purchased skim milk, $20 \%$ purchased it for its nutritional aspects, and only $11 \%$ purchased it for flavor. A family member's preference was indicated as another primary reason (13\%) for purchasing skim milk. Milk packaged in plastic was purchased regularly by $84 \%$ of the participants, followed by $12 \%$ in paperboard, $0 \%$ in glass, and $4 \%$ in another type of packaging; $61 \%$ of participants purchased milk in gallons, $30 \%$ in half-gallons, $8 \%$ in quarts, and $1 \%$ in single-serve packages.

Selected pre-survey questions and responses are included in Table 3. Pre-surveys revealed a consumer perception that milk processing has a moderate to large effect on the flavor (76\%) and nutritional $(71 \%)$ attributes of milk. Although $68 \%$ perceived that milk flavor is affected moderately to a lot by code date, $84 \%$ checked the code date on milk "every time," and $71 \%$ consciously looked for milk with the code date that was farthest out. The pre-survey also revealed that $85 \%$ of participants in our auctions had experienced "bad" milk (Table 3). Although we provided no definition of "bad" to participants (they were encouraged to write in the description), the majority had a personal sense of the term.

Although trained panelists detected oxidized off-flavor in milk from translucent HDPE packaging, consumers did not have a significant preference for milk in paperboard over milk in translucent HDPE when they were served blind-coded samples in pairs $(P>0.05$; data not shown). Previous work has shown that consumers can detect differences between untreated milk and milk exposed to light after approximately $54 \mathrm{~min}$ (Chapman et al., 2002), and our trained panelists detected oxidized off-flavor in the same samples provided to the consumer panelists. Thus, these findings suggest that these participants did not notice the oxidized flavor or did not consider it objectionable enough to prefer the milk from paperboard. Because translucent HDPE is so common in the marketplace, it is likely that consumers are accustomed to oxidized milk flavor and accept it as standard. In summary, oxidized flavor may not be a major dictator of the selection of milk package types.

We were interested whether participants had a preference for milk from HDPE or paperboard, but we were also interested in the overall acceptability of each milk option. Preference testing means little if both samples are disliked very much, so it was important to know the extent of acceptability. Multi-factor ANOVA of the hedonic scores revealed few significant differences. Only the scores for skim milk packaged in HDPE were influenced by the fat content typically purchased $(P<$ 0.05); mean scores were higher for skim milk purchasers (5.37) than for those who regularly purchased $1 \%$ milk (3.94) or whole milk (3.73). Hedonic scores for $2 \%$ milk packaged in HDPE, and for skim and $2 \%$ milk packaged in paperboard, were not influenced by fat content typically purchased or package typically purchased $(P$ $>0.05$ ), and we found no package $\times$ fat content interactions $(P>0.05)$. For ease of communicating results, we pooled all data by sample type (skim HDPE, skim paperboard, $2 \%$ HDPE, and $2 \%$ paperboard) and analyzed them using 1-way ANOVA (Table 4).

In all cases, central tendencies were seen for milk acceptability scores, with mean scores hovering around 5.0 out of 7.0 ; milk samples were liked slightly by panelists (Table 4). However, although we found no differences in consumers' acceptability scores between milks of the same fat content in different packaging $(P>$ 
Paterson and Clark: AUCTIONS TO ASSESS MILK PACKAGING VALUE

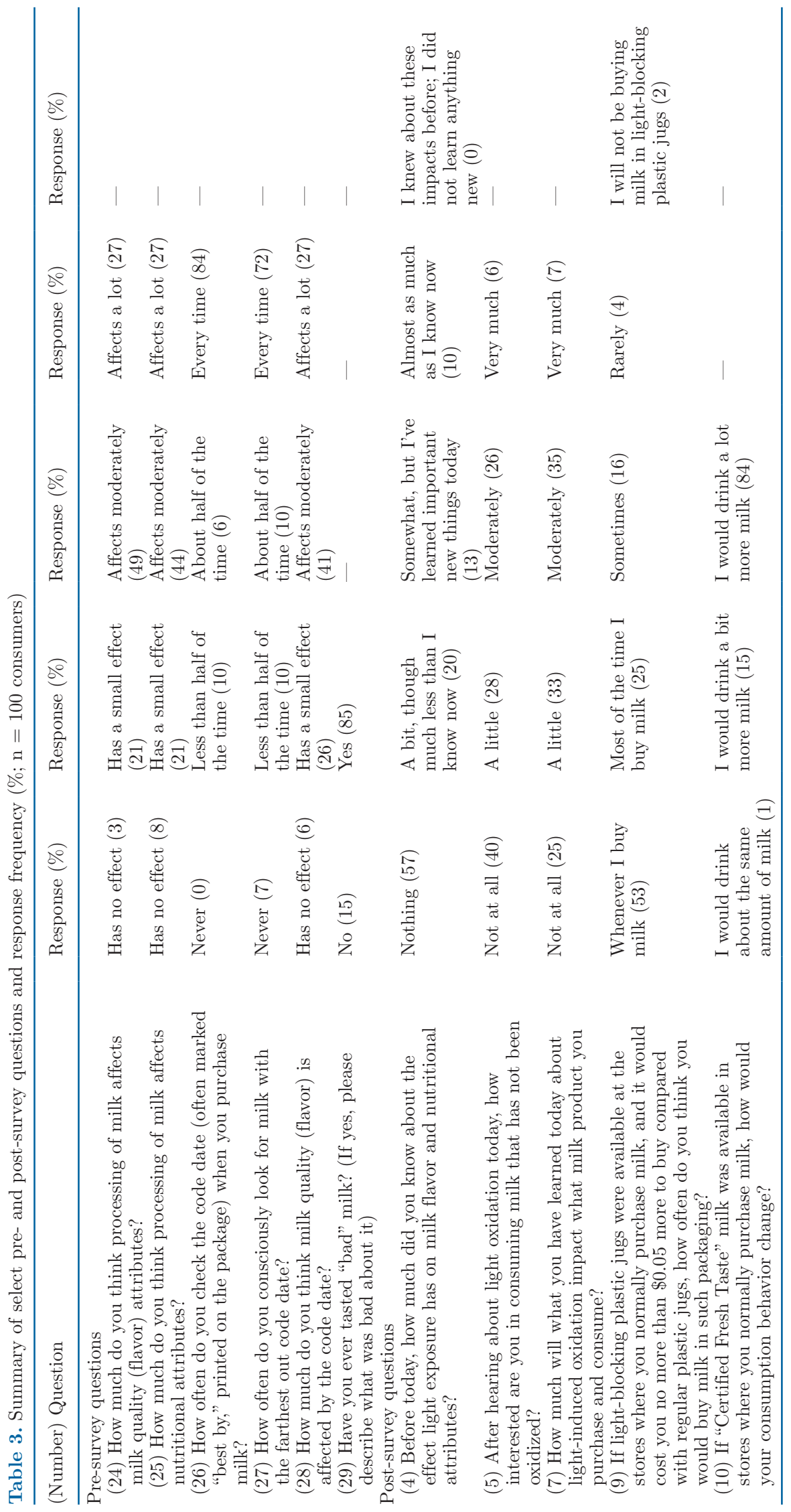


Table 4. Mean consumer acceptability score and value (US\$) for skim and $2 \%$ milk from different packaging assessed in round 1 auction $(\mathrm{n}=$ 100)

\begin{tabular}{|c|c|c|c|c|c|c|}
\hline Sample $^{1}$ & $\begin{array}{c}\text { Mean } \\
\text { acceptability score }\end{array}$ & $\begin{array}{l}\text { Mean bid } \\
\text { value }(\$)\end{array}$ & $\begin{array}{l}\text { Minimum } \\
\text { bid }(\$)\end{array}$ & $\begin{array}{l}\text { Maximum } \\
\text { bid }(\$)\end{array}$ & $\begin{array}{l}\text { Median } \\
\text { bid }(\$)\end{array}$ & $\begin{array}{l}\text { Geometric } \\
\text { mean bid }(\$)\end{array}$ \\
\hline Skim HDPE & $4.8^{\mathrm{a}}$ & $1.03^{\mathrm{a}}$ & 0.00 & 2.63 & 1.00 & 1.27 \\
\hline Skim paperboard & $4.7^{\mathrm{a}}$ & $1.00^{\mathrm{a}}$ & 0.00 & 3.79 & 1.00 & 1.28 \\
\hline $2 \%$ paperboard & $5.2^{\mathrm{b}}$ & $0.77^{\mathrm{a}}$ & 0.00 & 3.50 & 0.13 & 1.32 \\
\hline
\end{tabular}

${ }^{\mathrm{a}, \mathrm{b}}$ Means in the same column with different superscripts were significantly different $(P<0.05)$; scores based on 7 -point hedonic scale $(1=$ dislike very much; 7 = like very much).

${ }^{1} \mathrm{HDPE}=$ high-density polyethylene.

0.05), consumers' mean acceptability scores for $2 \%$ in paperboard were higher $(P<0.05)$ than for skim in paperboard and skim in HDPE. Because panelists did not see the package the milk came from, the higher acceptability of $2 \%$ in paperboard did not indicate a preference for packaging, but rather an increased liking for the higher-fat product based upon taste/flavor or mouth feel. Of the consumers who regularly purchased skim milk (47\%), only $11 \%$ purchased it for flavor; $20 \%$ indicated purchasing skim milk for nutritional reasons. As well, only about half of the $46 \%$ of participants who purchased skim milk regularly gave the skim milk higher acceptability scores. Consumption of low-fat and nonfat dairy milk was encouraged by the Dietary Guidelines for Americans (DHHS-USDA, 2010) in circulation at the time. These factors could partially explain the high frequency of skim milk purchased, even though the $2 \%$ milk received higher acceptability scores; consumers may prefer the taste of $2 \%$ milk but purchase skim milk for other reasons.

At least $83 \%$ of the participants bought plastic packaging, but only about half of those gave milk from translucent HDPE a higher acceptability score. This confirms that although consumers bought one type of packaging regularly, they did not necessarily purchase it because of a perceived superior flavor.

\section{Auctions}

Rather than presenting data in tables by fat content (skim or $2 \%$ milk) or packaging type (HDPE or paperboard) we have summarized the data by product types available for bidding and by round in Tables 4, 5, and 6. Outlier analysis tools revealed that 4 panelists were high bidders for milk they wanted to buy. Because so many bids were $\$ 0.00$, high bidders tended to stand out. However, when we tested bids during the practice rounds (with candy bars) for a session effect, we found none, and the candy bar bids did not correlate with the milk bids. Panelists who bid high for milk were not simply high bidders; they wanted the milk. Because the values entered for high bidders were not mistakes in data entry, they were not erratic bidders, and because the high number of $\$ 0.00$ bids made high bidders stand out, we could not justify removing the data. Data transformation for analysis of margins (discussed later) eliminated the effect of outliers in the data set.

Consumers' initial (round 1) mean values for milk (after 4 options were displayed) ranged from $\$ 0.77$ to $\$ 1.03$ per half-gallon (Table 4). Although the values appear quite low considering the true market price for milk at the time ( $\$ 2.19$ to $\$ 3.99$ per half-gallon), it is important to note that the panelists were not told in

Table 5. Summary of consumer value (US\$) bids for skim and $2 \%$ milk from different packaging assessed in the round 2 auction $(\mathrm{n}=100)$

\begin{tabular}{|c|c|c|c|c|}
\hline Sample option on bidding sheet ${ }^{1,2}$ & Actual identity ${ }^{3}$ & Mean & Median & $\begin{array}{c}\text { Geometric } \\
\text { mean }\end{array}$ \\
\hline Skim HDPE tasted like sample 324 & Skim milk from HDPE (oxidized off-flavor) & $0.79^{\mathrm{a}}$ & 0.50 & 1.03 \\
\hline Skim HDPE tasted like sample 604 & Skim milk from HDPE (not oxidized) & $0.85^{\mathrm{a}}$ & 0.75 & 1.04 \\
\hline Skim paperboard tasted like sample 324 & Skim milk from paperboard (oxidized off-flavor) & $0.69^{\mathrm{a}}$ & 0.50 & 0.97 \\
\hline Skim paperboard tasted like sample 604 & Skim milk from paperboard (not oxidized) & $0.78^{\mathrm{a}}$ & 0.50 & 1.01 \\
\hline $2 \%$ HDPE tasted like sample 549 & $2 \%$ milk from HDPE (oxidized off-flavor) & $0.76^{\mathrm{a}}$ & 0.50 & 1.09 \\
\hline $2 \%$ HDPE tasted like sample 535 & $2 \%$ milk from HDPE (not oxidized) & $0.83^{\mathrm{a}}$ & 0.58 & 1.18 \\
\hline $2 \%$ paperboard tasted like sample 549 & $2 \%$ milk from paperboard (oxidized off-flavor) & $0.79^{\mathrm{a}}$ & 0.50 & 1.05 \\
\hline $2 \%$ paperboard tasted like sample 535 & $2 \%$ milk from paperboard (not oxidized) & $0.81^{\mathrm{a}}$ & 0.50 & 1.09 \\
\hline
\end{tabular}

${ }^{\mathrm{a}}$ Means in the same column with different superscripts were significantly different $(P<0.05)$.

${ }^{1} \mathrm{HDPE}=$ high-density polyethylene.

${ }^{2}$ The 3 -digit codes listed are from 1 of the 11 sessions (to help the reader visualize the panelist experience). Panelists were asked to assess a value for each product on the bidding sheet based on their particular 3-digit-coded samples.

${ }^{3}$ Actual packaging and the presence or absence of oxidized off-flavor was not revealed to consumers. 
advance that milk would be available for sale, nor were they told to bring money. The most common bid on all half-gallon milk products in all rounds was $\$ 0.00$, which was typical. Participants were explicitly told to bid $\$ 0.00$ if they did not want to purchase a product. In fact, in an auctions study of fish products (Alfnes et al., 2018), $\$ 0.00$ bids ranged from 11 to $75 \%$ of all bids. However, not wanting a product does not mean someone does not like the product. Consumers may have had milk at home, may not have brought money with them, and may have had plans for the $\$ 30$ we gave them. This is why we asked "What is your current stock of milk at home?" and tested the potential effects of when the $\$ 30$ incentive was paid, and of asset integration.

Twenty-four participants (24\%) indicated that they were almost out of milk at home. However, when this variable was included in multi-factor ANOVA, stock at home was not a significant factor affecting bids. Other purchasing and consumption behavior factors discussed later had a greater effect on consumer bidding.

Multi-factor ANOVA of study-design factors revealed that whether panelists were paid at the beginning or the end of the session was not a significant factor affecting bids, but asset integration and the asset integration $\times$ paid first interaction were significant factors. Whether panelists were asked to think about what they would use the $\$ 30$ for (asset integration) was a significant factor for 12 of the 20 milk options: those who participated in asset integration bid more $(P<0.05)$ than those who did not. This finding was in contrast to what we expected, because when the money at stake is viewed as the person's own money (the goal of asset integration), people display reluctance to participate in risky behavior (in our case, high bidding; Morrison and Oxoby, 2019). However, this finding is substantiated in our companion paper (Paterson and Clark, 2020).

For the interaction of asset integration $\times$ paid first, mean bids were higher $(P<0.05)$ from those who participated in asset integration at the beginning and were paid at the end, than from those who participated in asset integration but were paid at the beginning for 11 of the 20 milk options. We saw this for skim milk packaged in HDPE in round 1; $2 \%$ milk in round 2 that was not oxidized, packaged in paperboard or HDPE; skim milk in round 2 that was oxidized, packaged in paperboard; and all available options in round 3 except $2 \%$ in HDPE or paperboard that was not certified. As well, for 7 of the 20 products, those who participated in asset integration at the beginning and were paid at the end bid more $(P<0.05)$ than those who did not participate in asset integration and were paid at the end. This was true for $2 \%$ milk in round 2 , available in paperboard or HDPE that was not oxidized, and for all certified milk options in round 3 . These significant interactions suggest that some who participated in asset integration and were paid at the end may have been sensitive to milk without oxidized off-flavor and more willing to pay a premium for it than those who did not participate in asset integration and were paid at the end.

Removal of one of the highest bidders did not reduce the effect of asset integration (significant for 11 of the 20 products) but it did reduce the effect of the interaction (significant for 6 of the 20 products) on bids. This finding suggests that asset integration had a real effect on bids, but 1 panelist played a strong role in the interaction effect. In summary, asking panelists to think about how they would spend the $\$ 30$ (asset integration) resulted in higher mean bids for milk. Something other than the amount of milk at home influenced this behavior, because 2-way ANOVA confirmed no stock $\times$ asset interaction effect.

Many factors influence the value consumers are willing to pay at the time of auction (Alfnes et al., 2018), and this in part explains the wide range of bids we found on half-gallon milk options in round 1 (\$0.00 to $\$ 3.79), 2$ (\$0.00 to $\$ 5.00)$, and 3 (\$0.00 to $\$ 4.75)$. The geometric mean, which reduces the effects of extremes in data sets, may better reflect the value panelists had

Table 6. Summary of consumer value bids (US\$) for skim and $2 \%$ milk from different packaging assessed in the round 3 auction $(\mathrm{n}=100)$

\begin{tabular}{|c|c|c|c|}
\hline Sample option ${ }^{1}$ & Mean & Median & $\begin{array}{c}\text { Geometric } \\
\text { mean }\end{array}$ \\
\hline Skim HDPE (no seal) & $0.74^{\mathrm{ab}}$ & 0.63 & 0.99 \\
\hline Skim paperboard (no seal) & $0.82^{\mathrm{ab}}$ & 0.75 & 1.06 \\
\hline Skim light-block HDPE ("Certified Fresh Taste" seal) & $0.95^{\mathrm{ab}}$ & 1.00 & 1.27 \\
\hline Skim paperboard ("Certified Fresh Taste" seal) & $0.97^{\mathrm{ab}}$ & 1.00 & 1.31 \\
\hline $2 \%$ HDPE (no seal) & $0.61^{\mathrm{b}}$ & 0.00 & 1.09 \\
\hline $2 \%$ paperboard (no seal) & $0.79^{\mathrm{ab}}$ & 0.50 & 1.09 \\
\hline $2 \%$ light-block HDPE ("Certified Fresh Taste" seal) & $0.99^{\mathrm{ab}}$ & 1.00 & 1.23 \\
\hline $2 \%$ paperboard ("Certified Fresh Taste" seal) & $1.10^{\mathrm{a}}$ & 1.00 & 1.33 \\
\hline
\end{tabular}

$\overline{\mathrm{a}, \mathrm{b}}$ Means in the same column with different superscripts were significantly different $(P<0.05)$.

${ }^{1} \mathrm{HDPE}=$ high-density polyethylene. 
for the available half-gallon options $(\$ 1.27$ to $\$ 1.37$ in round $1, \$ 0.97$ to $\$ 1.18$ in round 2 , and $\$ 0.99$ to $\$ 1.33$ in round 3 ).

Bids in round 2 demonstrated that the addition of sensory information did not increase consumers' perceived value of the half-gallons of milk (Table 5). In fact, mean, median and geometric mean bids for all skim milk options decreased compared with round 1 , in which only packaging and fat content information were known by panelists. Mean values for $2 \%$ milk remained essentially the same as round 1 , but maximum values for $2 \%$ milk increased numerically. Information gained during the sensory experience influenced consumer value for skim milk more than for $2 \%$ milk. Rather than increasing their bids to reflect their similar liking for skim and $2 \%$ milk, they reduced their bids for skim milk closer to their initial value for $2 \%$ milk.

In round 3, with all information revealed, panelists demonstrated their value for milk with a "Certified Fresh Taste" seal (Table 6). Even though consumers generally did not notice oxidized off-flavors [based on the fact that acceptability scores and monetary values did not differ based upon packaging alone (round 1) or packaging coupled with sensory evaluation (round 2)], after hearing an educational message about the effect of light on milk flavor and nutrition, tasting skim and $2 \%$ milk from light-block HDPE, and having the option of "Certified Fresh Taste" milk to purchase, consumers assigned higher values to milk with a "Certified Fresh Taste" seal than to their equivalent counterparts without the seal in round $3(P<0.05$; Table 6$)$. The values consumers assessed for milks with "Certified Fresh Taste" seals in round 3 (\$0.95 to $\$ 1.10$ per half- gallon) were similar to or higher than the values they assessed for milk in the first round ( $\$ 0.77$ to 1.00 per half-gallon). This finding may suggest that consumers had in mind how much they were willing to pay for milk going into the auctions, and desire for a given milk simply shifted based on information learned during the auctions. This concept is discussed further related to margins, next. The results presented so far confirm that consumers valued the idea of a fresh-tasting product, even when they did not personally notice a difference in taste.

To further evaluate the effect of the educational message and "Certified Fresh Taste" seal on individual consumer value for milk, we calculated differences (margins) between bids in later and earlier rounds by subtracting individual bids for the "same milk" (same fat content and package type) in round 2 from round 1 (to evaluate the value of sensory experience), by subtracting bids for round 2 from round 3 (to evaluate the value of certification over sensory experience), and by subtracting bids for round 3 from round 1 (to evaluate the value of certification and sensory experience over simply seeing a package). This process eliminated the session-by-session variability in bidding, and reflected differences in values perceived by individuals. The 1-way ANOVA of bid margins are summarized in Table 7 .

When rounds 1 and 2 were compared (Table 7, light gray shading), bid margins were almost zero for $2 \%$ milk, meaning that panelists did not change their bids for $2 \%$ milk based on taste. In contrast, individual skim milk bids dropped from round 1 to round 2 , by $\$ 0.26$ on average (Table 7 ). Because round 2 took place after

Table 7. Differences in consumers' bids (US\$) between rounds ${ }^{1}$ (later bid subtracted from earlier bid) for the same milk (same fat content and package type; $\mathrm{n}=100)$

\begin{tabular}{|c|c|c|c|c|}
\hline Auction round, available product ${ }^{2}$ & $\begin{array}{l}\text { Margin from same } \\
\text { milk, not oxidized, } \\
\text { round } 2\end{array}$ & $\begin{array}{l}\text { Margin from same } \\
\text { milk, oxidized, } \\
\text { round } 2\end{array}$ & $\begin{array}{l}\text { Margin from same } \\
\text { milk, not certified, } \\
\text { round } 3\end{array}$ & $\begin{array}{l}\text { Margin from same } \\
\text { milk, certified, } \\
\text { round } 3\end{array}$ \\
\hline $\begin{array}{l}\text { Round 1, skim milk, HDPE, oxidized } \\
\text { Round 1, skim milk, paperboard, not oxidized } \\
\text { Round 1, } 2 \% \text { milk, HDPE, oxidized } \\
\text { Round } 1,2 \% \text { milk, paperboard, not oxidized }\end{array}$ & $\begin{array}{c}-\$ 0.20^{\mathrm{ab}} \\
-\$ 0.24^{\mathrm{ab}} \\
\$ 0.04^{\mathrm{a}} \\
\$ 0.02^{\mathrm{a}}\end{array}$ & $\begin{aligned}-\$ 0.27^{\mathrm{ab}} \\
-\$ 0.34^{\mathrm{b}} \\
\$ 0.02^{\mathrm{ab}} \\
\$ 0.00^{\mathrm{a}}\end{aligned}$ & $\begin{array}{r}-\$ 0.32^{\mathrm{C}} \\
-\$ 0.17^{\mathrm{C}} \\
-\$ 0.17^{\mathrm{C}} \\
\$ 0.01^{\mathrm{ABC}}\end{array}$ & $\begin{array}{r}-\$ 0.11^{\mathrm{BC}} \\
-\$ 0.05^{\mathrm{BC}} \\
\$ 0.24^{\mathrm{AB}} \\
\$ 0.32^{\mathrm{A}}\end{array}$ \\
\hline
\end{tabular}

a,b; A-C; $\mathrm{x-}$ Different superscripts indicate significant differences between margins within the section $(P<0.05)$.

${ }^{1}$ Round 1 bid after package viewing; round 2 bid after sensory evaluation (sample identity not revealed); round 3 bid after educational message (sample identity revealed).

${ }^{2} \mathrm{HDPE}=$ high-density polyethylene. 
tasting 3-digit-coded samples, this finding indicated that panelists did not like the taste of the skim milk very much, and bid less on all 4 skim milk options after tasting.

Between rounds 2 and 3, panelists tasted milk from light-block HDPE and were asked to bid on milk with and without the "Certified Fresh Taste" seal. Panelists bid more for half-gallons of milk in light-block HDPE and paperboard with "Certified Fresh Taste" seals (in round 3) than they did for milk in translucent HDPE and paperboard (without certification seals) in rounds 1 and 2 (Table 7, far right column) with only 2 exceptions (discussed below). From rounds 2 to 3, we saw an increase in value for all milk with the "Certified Fresh Taste" seal (Table 7, far right column, unshaded section). Panelists bid an average of $\$ 0.25$ more for certified $2 \%$ milk and $\$ 0.18$ more for certified skim milk in round 3 than in round 2 . In contrast, milk that did not contain the "Certified Fresh Taste" seal was valued, on average, $\$ 0.05$ less in round 3 than in round 2 .

When we compared rounds 1 and 3 (Table 7, first 4 rows; columns 3 and 4), we found that panelists bid and average of $\$ 0.28$ more for $2 \%$ milk with the "Certified Fresh Taste" seal in round 3 than for $2 \%$ milk in paperboard or HDPE in round 1. In contrast, the $2 \%$ milk without the "Certified Fresh Taste" in round 3 was valued an average of $\$ 0.08$ less than $2 \%$ milk in paperboard or HDPE in round 1. For skim milk, similar to what we found in round 2, panelists bid less for skim milk in round 3 than in round 1 . They bid an average of $\$ 0.08$ less for skim milk in round 3 than in round 1 . The lack of increase in bids for "Certified Fresh Taste" skim milk compared with round 1 was partially explained by the drop in bids for skim milk in round 2. Although we found a partial recovery in value when packages were labeled with the "Certified Fresh Taste" seal, participants did not value skim milk as much in round 3 as they did in round 1. Participants may have liked the flavor of the $2 \%$ milk more than they expected, and more than they liked the skim milk. Skim milk without the "Certified fresh Taste" in round 3 was valued an average of $\$ 0.25$ less than skim milk in paperboard or HDPE in round 1.

The differences in margins across rounds and milk types may also reveal that panelists learned something from the educational message. In round 3, panelists bid an average of $\$ 0.10$ more for skim milk in paperboard without the "Certified Fresh Taste" seal than for skim milk they tasted in round 2 . In contrast, the margins in bids for $2 \%$ milk in paperboard between rounds 2 and 3 were almost zero. The fact that all milk packaged in HDPE without the "Certified Fresh Taste" seal was valued less in round 3 than the same milk in round 2 suggests that, after the educational message, panelists understood that light penetrates milk in translucent packaging and affects it in a negative way, and they bid less for milk in translucent HDPE in round 3 as a result.

To summarize these findings, the positive margins for "Certified Fresh Taste" milk showed evidence that consumers strongly valued fresh-tasting milk, even though their hedonic and preference scores indicated they could not tell a difference between non-oxidized and oxidized milk. Although we did not find other work related to the effect of product freshness labeling, our findings aligned with those of others who reported a general increase in willingness to pay for products with labeling terminology related to organic, such as "natural," "humane," and "containing no genetically modified ingredients" (Napolitano et al., 2008; Teuber et al., 2016; DeLong and Grebitus, 2018). However, certification labels do not always command a higher price. Experimental auction work by Elbakidze et al. (2013) revealed that consumers were willing to pay a premium for a unit of ice cream labeled "Humane animal care certified" but were not willing to pay a higher price for cheese with the same label.

Although predictor screening revealed that the purchasing and consumption variables "fat content typically purchased," "package typically purchased," and "frequency of consumption" were the greatest predictors of variability in the data set, none of them were highly correlated with auction bids or hedonic scores (r $<0.45)$. Nonetheless, we found a tendency for consumers of $2 \%$ and whole milk to bid less for skim milk (r $>0.23$ ), and for those who purchased milk in glass or plastic to bid less for milk in paperboard $(\mathrm{r}>0.25)$. As well, most bids for $2 \%$ milk were highly correlated ( $\mathrm{r}>$ $0.55)$ within and across rounds) and were distinct from (not correlated with) all bids for skim milk products, most of which were correlated $(\mathrm{r}>0.50$ within and across rounds), suggesting that panelists were driven by the fat content they preferred, not necessarily by what they typically purchased. Some of the participants purchased milk for reasons other than flavor preference (family member preference, nutritional attributes, price, other), and this may explain why fat content typically purchased and package typically purchased did not correlate with hedonic scores or bids.

We then used $k$ means cluster analysis to better distinguish characteristics of bidding populations (Table 8). In each round, 4 distinct clusters were revealed with $\mathrm{n} \geq 5$ (5\% of the population). For round 1, cluster 1 was composed of 14 consumers who primarily purchased $1 \%$ and $2 \%$ milk in either HDPE or paperboard, and who consumed milk multiple times a week to daily. These consumers tended to bid high (average $\$ 2.22$ ) for all available milk options. Cluster 2 was composed 
of 30 consumers who primarily purchased $2 \%$ milk in HDPE and consumed milk multiple times a week to daily. These consumers tended to bid higher for $2 \%$ milk (average $\$ 0.85$ ) than skim (average $\$ 0.30$ ). Cluster 3 was composed of 9 consumers who purchased primarily $2 \%$ and whole milk in paperboard, and consumed milk weekly or multiple times a week. These consumers bid higher for milk in paperboard (average \$1.29) than HDPE (average $\$ 0.25$ ). Cluster 4 was composed of 45 consumers who purchased primarily skim and $1 \%$ milk in HDPE and consumed milk daily or multiple times a day. These consumers had the highest mean for frequency of consumption and bid higher for skim milk (average $\$ 1.25$ ) than for $2 \%$ milk (average $\$ \$ 0.20$ ). In summary, in the first round, when panelists could only see the packaging, the majority of participants (75\%) were driven by the milk fat content of the product options.

For round 2, cluster 1 was composed of 9 consumers who purchased primarily $2 \%$ milk in HDPE and con- sumed milk weekly to multiple times per week. These consumers bid higher for $2 \%$ milk (average $\$ 2.50$ ) than for skim milk (average \$0.99). Cluster 2 was composed of 59 consumers who purchased primarily $1 \%$ milk in HDPE and consumed milk daily. These consumers tended to bid low on all milk options (average $\$ 0.45$ ) in round 2. Cluster 3 was composed of 8 consumers who purchased primarily $2 \%$ and whole milk in paperboard and consumed milk weekly to multiple times per week. These consumers appear to have a distaste for oxidized milk, because they tended to bid higher for the specific options that would not be oxidized-skim or $2 \%$ packaged in paperboard (average \$1.09) — than for oxidized milk or milk packaged in HDPE (average $\$ 0.62$ ). This finding demonstrated that panelists took the auction process seriously (bids were not erratic), the sensory experience had a direct effect on bidding, and some panelists were likely sensitive to the oxidized off-flavor and bid higher for products that met their expected level of quality at the fat content of their preference.

Table 8. Cluster means of auction bids (US\$) resulting from $k$ means cluster analysis of each auction round

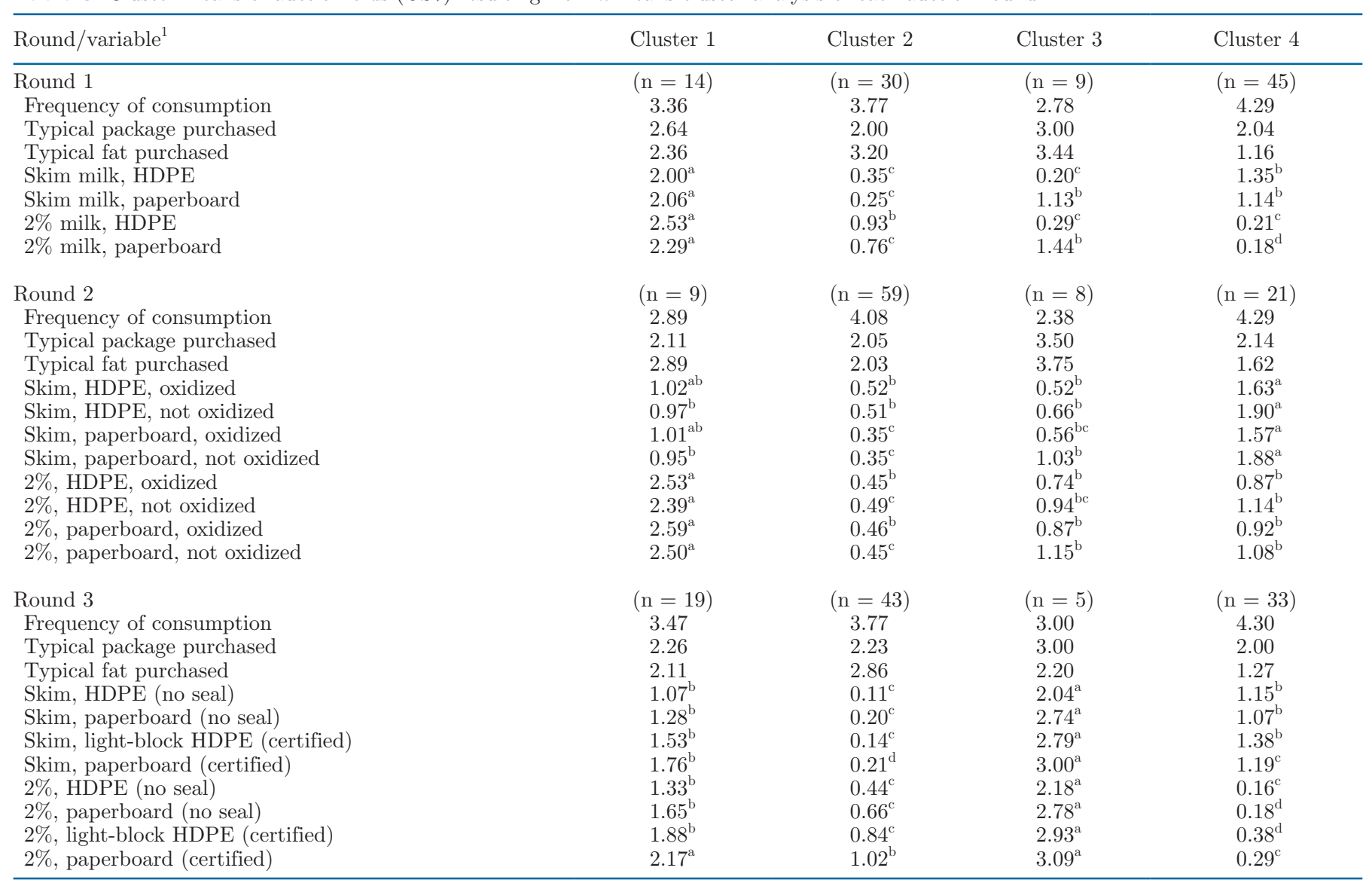

${ }^{\mathrm{a}-\mathrm{d}}$ Different superscripts indicate that significant differences exist between bid means in the same row $(P<0.05)$.

${ }^{1} \mathrm{HDPE}=$ high-density polyethylene. 
Cluster 4 was composed of 21 consumers who purchased primarily skim and $1 \%$ milk in HDPE and consumed milk daily to multiple times per day. These consumers tended to bid higher for skim milk (average \$1.75) than for $2 \%$ milk (average $\$ 1.00$ ). In summary, in round 2 , when panelists were asked to consider their sensory experience in bidding, the proportion of participants who were driven primarily by milk fat content dropped (40\%), and a high proportion (59\%) fell into the lowbidding cluster. The complexity of the task in round 2 could partially explain why. Participants were asked to bid on milk in paperboard or HDPE based on their sensory experience. Not knowing for certain which sample they may end up with after the auction (the "binding round") added a level of risk to this round of bids and may have increased the number of low bids. Such an assertion aligns with the notion of Morrison and Oxoby (2019) that people display reluctance to participate in risky behavior (in our case defined as high-bidding) when money is at stake. The persistence of a highbidding group, although it decreased in size from round 1 , showed that some participants sincerely wanted to purchase milk or were perhaps not risk-averse.

For round 3, cluster 1 was composed of 19 consumers who purchased primarily $1 \%$ and $2 \%$ milk in paperboard and HDPE, and consumed milk multiple times per week to daily. These consumers bid higher for certified $2 \%$ (average $\$ 2.03$ ) than for other milk options (average $\$ 1.44$ ) in round 3. Cluster 2 was composed of 43 consumers who purchased primarily $1 \%$ and $2 \%$ milk in paperboard and HDPE and consumed milk multiple times per week to daily. These consumers bid higher for certified $2 \%$ (average $\$ 0.93$ ) than for other milk options (average $\$ 0.29$ ) in round 3. Cluster 3 was composed of 5 consumers who purchased primarily $1 \%$ and $2 \%$ milk in paperboard and consumed milk multiple times per week. Although they bid high for all options, these consumers bid higher for milk with the "Certified Fresh Taste" seal (average \$3.46) than for options without it (average \$2.44). Cluster 4 was composed of 33 consumers who purchased primarily skim and $1 \%$ milk in HDPE and consumed milk multiple times per day. Consumers bid higher for certified skim milk (average $\$ 1.20$ ) than for other milk options (average \$0.25) in round 3 . In summary, the $k$ means cluster analysis of round 3 bids again confirmed the effect of the "Certified Fresh Taste" seal on bids: all clusters exhibited higher mean bids for certified than for noncertified milk. We distinguished 3 clusters based on whether consumers bid higher for skim or $2 \%$ milk. One cluster included the highest-bidding individuals $(\mathrm{n}=5)$, who appeared very interested in taking milk of any kind home, but still bid higher for milk with "Certified Fresh Taste" than for milk without the seal.

\section{Consumer Post-Survey}

By providing an educational message about lightinduced oxidation and the effect of packaging on milk, we intended that consumers would be more aware of the options available in the market to ensure a positive fluid milk experience. The post-survey revealed improved understanding of the effect of light on milk, interest in milk that was not oxidized, and willingness to purchase milk in light-block packaging. Responses to select questions in the post-survey are included in Table 3 . The post-surveys indicated that before the session, $57 \%$ of panelists knew nothing about the effect of light on milk. After learning about it, $64 \%$ indicated that they were at least moderately interested in consuming non-oxidized milk. This is particularly interesting, because their acceptability scores did not indicate a higher liking for the non-oxidized sample. Nonetheless, based on their bids, consumers valued the "Certified Fresh Taste" seal. Fifty-nine percent also indicated that their purchasing and consumption would be at least moderately affected by the information presented during the session.

When asked how often they would purchase milk in a light-block package (if only $\$ 0.05$ more per package), over $75 \%$ said they would buy it most of the time or every time going forward. Most remarkably, however, was the fact that $84 \%$ of respondents indicated they would "drink a lot more milk" if "Certified Fresh Taste" milk was available in the market (Table 3 ). This finding in particular demonstrates consumers' strong aversion to "bad" milk. As noted above, we did not define "bad" for them: $84 \%$ indicated in the pre-survey that they had tasted "bad" milk before. With the shrinking fluid milk market, these findings underline the importance of freshness messaging so that dairy products can compete with longer-shelf-life products that dominate the market to maintain fluid milk customers.

\section{Limitations}

The study was conducted from March to April 2013 in Ames, Iowa. Although it was completed more than $6 \mathrm{yr}$ ago, this work is still relevant for several reasons. Auctions have rarely been applied to dairy products, and even fewer studies report a sensory evaluation or educational component. The fluid milk industry is a competitive marketplace, so the information revealed here regarding consumer choices and preferences for milk of different fat content and packaging, effect of sensory experience and educational messages, and willingness to pay for specific milk quality characteristics is important. Experimental auctions have been shown to more accurately reflect the amount consumers are will- 
ing to pay for products than hypothetical experiments. The fact that consumers were willing to pay more for milk with a "Certified Fresh Taste" seal underlined the importance of external cues about freshness to consumers.

\section{CONCLUSIONS}

Milk in translucent HDPE exposed to light similar to that of a retail dairy case had higher trained panelist scores for oxidized off-flavor than milk in paperboard packaging, but untrained panelists did not notice a difference between milks from the different packaging types. Milk with an oxidized off-flavor did not receive significantly lower acceptability scores or auction values from consumers, indicating that most were not offended by the oxidized off-flavor enough to alter their value for the products. Nonetheless, although panelists assessed no difference in value for milk in HDPE or paperboard in early auction rounds, after learning about the effect of light on milk in translucent packaging and being offered a "Certified Fresh Taste" seal on milk protected from light, consumers assessed significantly higher values for light-block and paperboard packaging with the "Certified Fresh Taste" seal than for milk in translucent HDPE. We observed this finding regardless of participants' typical milk package or fat content purchasing practices. Behaviors and perceptions of milk in different packaging appear to be influenced more by packaging information than by actual sensory experience, and fat content appears to be the primary driver in milk purchasing choice.

\section{ACKNOWLEDGMENTS}

This research was funded partially by the dairy farmers of Iowa, through the Midwest Dairy Association (now Midwest Dairy), and partially by the Agricultural Utilization Research Institute (AURI). Special thanks are extended to Agropur Inc. Division Natrel USA, who donated all of the milk for the study, and to Marin Bozic, who not only made the arrangements with Agropur, but also consulted with us on the project and transported fresh milk from Minnesota to Iowa for these studies. We are also grateful for the staff of the Iowa State University Nutrition Wellness Research Center who facilitated our use of the center for auction sessions. We appreciate all of our auction participants and acknowledge the time and expertise provided by our trained panelists. We also acknowledge the support of Donald Beitz, Kenneth Prusa, Catherine Strohbehn, and Keith Vorst, who served as program of study committee members during Molly Paterson's PhD program. This article is a product of the Iowa Agriculture and
Home Economics Experiment Station, Ames, Iowa. Project No. IOW04002 is sponsored by Hatch Act and State of Iowa funds. The authors have not stated any conflicts of interest.

\section{REFERENCES}

Akaichi, F., R. M. Nayga Jr., and J. M. Gil. 2012. Assessing consumers' willingness to pay for different units of organic milk: Evidence from multiunit auctions. Can. J. Agric. Econ. 60:469-494. https:/ /doi.org/10.1111/j.1744-7976.2012.01254.x.

Alfnes, F., K. Rickertsen, and J. F. Shogren. 2018. Test-retesting in experimental valuation of perishable food products: unstable individual bids and reliable market demand. J. Agric. Econ. 69:382-392. https://doi.org/10.1111/1477-9552.12248.

Alvarez, V. B. 2009. Fluid milk and cream products. Pages 73-133 in The Sensory Evaluation of Dairy Products. S. Clark, M. Costello, M. A. Drake, and F. W. Bodyfelt, ed. Springer, New York, NY.

Black, R. E., S. M. Williams, I. E. Jones, and A. Goulding. 2002. Children who avoid drinking cow milk have low dietary calcium intakes and poor health. Am. J. Clin. Nutr. 76:675-680. https://doi.org/ 10.1093/ajcn/76.3.675.

Bohm, P. 1994. Behavior under uncertainty without preference reversal: A field experiment. Empir. Econ. 19:185-200. https://doi.org/ $10.1007 / \mathrm{BF} 01175871$.

Bus, A. E., and A. Worsley. 2003. Consumer's health perceptions of three types of milk: A survey in Australia. Appetite 40:93-100. https://doi.org/10.1016/S0195-6663(03)00004-7.

Chapman, K. W., H. T. Lawless, and K. J. Boor. 2001. Quantitative descriptive analysis and principal component analysis for sensory characterization of ultrapasteurized milk. J. Dairy Sci. 84:12-20. https://doi.org/10.3168/jds.S0022-0302(01)74446-3.

Chapman, K. W., L. J. Whited, and K. J. Boor. 2002. Sensory threshold of light-oxidized flavor defects in milk. J. Food Sci. 67:27702773. https://doi.org/10.1111/j.1365-2621.2002.tb08813.x.

DeLong, K. L., and C. Grebitus. 2018. Genetically modified labeling: The role of consumers' trust and personality. Agribusiness 34:266-282. https://doi.org/10.1002/agr.21521.

DHHS-USDA (Department of Health and Human Services-USDA). 2010. Dietary guidelines for Americans. 7th ed. Accessed Nov. 1, 2016. https://health.gov/dietaryguidelines/dga2010/ dietaryguidelines2010.pdf.

Donkor, O. N., A. Henriksson, T. Vasiljevic, and N. P. Shah. 2007. Galactosidase and proteolytic activities of selected probiotic and dairy cultures in fermented soymilk. Food Chem. 104:10-20. https: //doi.org/10.1016/j.foodchem.2006.10.065.

Elbakidze, L., R. M. Nayga Jr., and H. Li. 2013. Willingness to pay for multiple quantities of animal welfare dairy products: Results from random nth-, second-price, and incremental second-price auctions. Can. J. Agric. Econ. 61:417-438. https://doi.org/10.1111/j.1744 $-7976.2012 .01263 . x$

Hanley, N., J. F. Shogren, and B. White. 2006. Introduction to Environmental Economics. Oxford University Press, Oxford, UK.

Heaney, R. P., J. N. Keith, and R. L. Duyff. 2011. Unintended consequences of dairy avoidance. Accessed Oct. 9, 2016. https://www .nationaldairycouncil.org.

Hoffman, E., D. Menkhaus, D. Chakravarti, R. Field, and G. Whipple. 1993. Using laboratory experimental auctions in marketing research: A case study of new packaging for fresh beef. Mark. Sci. 12:318-338. https://doi.org/10.1287/mksc.12.3.318.

Jackson, K. A., and D. A. Savaiano. 2013. Lactose maldigestion, calcium intake and osteoporosis in African-, Asian-, and HispanicAmericans. J. Am. Coll. Nutr. 20:198S-207S.

Jaeger, S. R., and R. Harker. 2005. Consumer evaluation of novel kiwifruit: Willingness-to-pay. J. Sci. Food Agric. 85:2519-2526. https:/ /doi.org/10.1002/jsfa.2330.

Katz, A., N. Virk Hundal, Q. Yuan, and W. Shreffler. 2013. Cow's milk allergy: A new approach needed? J. Pediatr. 163:620-622. https://doi.org/10.1016/j.jpeds.2013.05.005. 
Kliem, K. E., and D. I. Givens. 2011. Dairy products in the food chain: Their impact on health. Annu. Rev. Food Sci. Technol. 2:21-36. https://doi.org/10.1146/annurev-food-022510-133734.

Lusk, J., and J. F. Shogren. 2009. Experimental Auctions: Methods and Applications in Economic and Marketing Research. Cambridge University Press, New York.

Morrison, W. G., and R. Oxoby. 2019. Asset integration, risk taking and loss aversion in the laboratory. IZA Institute of Labor Economics Discussion Paper Series. IZA DP No. 12268. Accessed Jul. 17, 2019. www.iza.org.

Napolitano, F., C. Pacelli, A. Girolami, and A. Braghieri. 2008. Effect of information about animal welfare on consumer willingness to pay for yogurt. J. Dairy Sci. 91:910-917. https://doi.org/10.3168/ jds.2007-0709.

O'Connor, T. P. and N. M. O'Brien. 2006. Lipid oxidation. Pages 557-600 in Advanced Dairy Chemistry. Vol. 2: Lipids. P. Fox and P. McSweeney, ed. Springer, New York, NY.

Paterson, M., and S. Clark. 2020. Use of auctions to assess consumer value for fresh and end of code milk. J. Dairy Sci. 103:4138-4150. https://doi.org/10.3168/jds.2019-17418.

Popkin, B. M. 2010. Patterns of beverage use across the lifecycle. Physiol. Behav. 100:4-9. https://doi.org/10.1016/j.physbeh.2009 .12 .022

Potts, H. L., K. N. Amin, and S. E. Duncan. 2017. Retail lighting and packaging influences consumer acceptance of fluid milk. J. Dairy Sci. 100:146-156. https://doi.org/10.3168/jds.2016-11673.

Rousu, M. D., D. C. Monchuk, J. F. Shogren, and K. M. Kosa 2005. Consumer willingness to pay for second-generation genetically engineered products and the role of marketing information. J. Agric. Appl. Econ. 37:647-657. https://doi.org/10.1017/ S1074070800027140.

Scurlock, A. M., L. A. Lee, and A. W. Burks. 2005. Food allergy in children. Immunol. Allergy Clin. North Am. 25:369-388. https:// doi.org/10.1016/j.iac.2005.02.005.
Sethi, S., S. K. Tyagi, and R. Anurag. 2016. Plant-based milk alternatives an emerging segment of functional beverages: A review. J. Food Sci. Technol. 53:3408-3423. https://doi.org/10.1007/s13197 $-016-2328-3$

Szilagyi, A., and N. Ishayek. 2018. Lactose intolerance, dairy avoidance, and treatment options. Nutrients 10:1994-2024. https://doi .org/10.3390/nu10121994.

Teuber, R., I. Dolgopolova, and J. Nordstrom. 2016. Some like it organic, some like it purple and some like it ancient: Consumer preferences and WTP for value-added attributes in whole grain bread. Food Qual. Prefer. 52:244-254. https://doi.org/10.1016/j.foodqual .2016.05.002.

USDA-ERS (Economic Research Service). 2019. Dairy data. Accessed May 16, 2019. https://www.ers.usda.gov/data-products/dairy -data/.

van Aardt, M., S. E. Duncan, J. E. Marcy, T. E. Long, and C. R. Hackney. 2001. Effectiveness of polyethylene terephthalate and high-density polyethylene in protection of milk flavor. J. Dairy Sci. 84:1341-1347. https://doi.org/10.3168/jds.S0022-0302(01)70164 $-6$.

Walsh, A. M., S. E. Duncan, H. L. Potts, and D. L. Gallagher. 2015 Comparing quality and emotional responses as related to acceptability of light-induced oxidation flavor in milk. Food Res. Int. 76:293-300. https://doi.org/10.1016/j.foodres.2015.02.027.

Webster, J. B., S. E. Duncan, J. E. Marcy, and S. F. O'Keefe. 2009 Controlling light oxidation flavor in milk by blocking riboflavin excitation wavelengths by interference. J. Food Sci. 74:S390-S398. https://doi.org/10.1111/j.1750-3841.2009.01336.x.

\section{ORCIDS}

Stephanie Clark @ https://orcid.org/0000-0002-3253-3042 